\title{
The Effect of Demonstrative Computer Simulation in Developing Intuition: Accomplishment of Acceleration Concept
}

\author{
Ali Baykal ${ }^{1}$, Gulsah Diyarbekir ${ }^{2}$ \\ Bogazici University ${ }^{1}$, Piri Pasha Primary School ${ }^{2}$, Turkey
}

\begin{abstract}
The purpose of this study is to see if students can develop the concept of acceleration without presenting the explicit knowledge but by demonstrative simulations instead. The questions to be answered in this study are:

i. Can students discriminate between two types of the motion, namely accelerated and constant velocity motion, by estimating the position of the objects at each unit time?

ii. Does being exposed to computer animation have a significant effect on discriminating between accelerated and constant velocity motions?

iii. Is there a significant relationship between subjects' science achievement score and their pre and post "Locate the Position" scale results?

The accelerated velocity is represented by a free fall of an apple from the tree. The constant velocity is presented by the flight of a bird towards the tree. The students marked the displacements of these two objects at six successive equal time intervals right after a real time demonstration. The simulations were run twice by slowing down the speeds at two stages. The students marked the displacements again after the slow motion demonstrations. Statistical analyses of student responses displayed significant improvements in achievement. Although not all of the students have achieved the expected outcomes many of them may use their experiences gained from simulations to construct more accurate mental models, and to form a bridge between real-world phenomena and scientific formalisms.
\end{abstract}

\section{Introduction}

Many scientists benefited from their intuitions to be able to make universally known discoveries. Archimedes, Newton, Mendeleev, Tesla and Einstein are the best known examples. Since the evolution of human brain is not as fast as knowledge expansion an average student of our time has to learn much more physics than Newton had ever discovered.
Conceptions of students about the natural world are quite different from those of scientists. We wonder if the intuition can be accelerated by some interventions despite Piaget's warning:

"In the area of logico-mathematical structures, children have real understanding only of that which they invent themselves, and each time that we try to teach them something too quickly, we keep them from reinventing it themselves. Thus, there is no good reason to try to accelerate this development too much; the time which seems to be wasted in personal investigation is really gained in the construction of method" [1; p. 435].

The nature and the nurture of conceptual change that starts with intuitive concepts are still secrecies to be demystified. We only know that the intuitive conceptions of students before learning are not easily alterable through direct instruction.

\section{Scene from the shoulders of giants}

Educators should take into account the students' intuitive knowledge in various domains in instructional design. Dykstra et al. [2] outlined ways that physics teachers could diagnose students' differing conceptions about the relationship between force and motion and then induce them to transform these conceptions. Educators should also activate their own cognitive forces to configure existing concepts through differential interventions, and enriched experiences. A variety of researchers converge on implicit learning. Reber defines implicit learning as "acquisition of knowledge that takes place largely independently of conscious attempts to learn and largely in the absence of explicit knowledge of what was acquired [3, p. 18]".

The product of implicit learning is often called tacit knowledge which has been defined as 'procedural knowledge that guides behavior but is not readily available for introspection'. Tacit knowledge has been found as a significant predictor of success. Successful individuals have extended tacit knowledge as well as having explicit knowledge essential for their discipline. Torff \& Sternberg 
asserts that tacit knowledge is a constructive force that wires learning in important contexts, in every setting [4]. According to them the failures in acquiring and using tacit knowledge when needed may underlie many difficulties that people show in school and in their job. Therefore the students should not only be taught the explicit knowledge required in a discipline (e.g. the formulas of physics), but they should also get tacit knowledge that is important in that discipline (e.g., how physicists conceptualize a project or how they make a discovery). the first step should be to analyze the tacit knowledge that is fundamental to a discipline, and the second step should be to design vehicles for curriculum and assessment hat teach both tacit and explicit knowledge required in the discipline. While Bowers et. al. [5] perceive individual differences in intuition Reber [3] expects limited or no individual differences in implicit learning and hence intuition. However, The central view about individual differences in intuition is that everyone has access to intuition, but there are individual differences in the speed and accuracy of usage. Intuitive conceptions may work both for and against educators and learners. To be able to determine the extent, to which a particular one is helpful or harmful, requires a detailed analysis of both the intuitive conception and the context in which it is used.

Apparently innovation begins within the embryo of intuition, is nourished by imagination and takes its shape by hard working. Rational knowledge and rational activities constitute the major part of scientific research, but they are not all. The rational part of research would be useless if it were not complemented by the intuition that gives scientists new insights and makes them creative. Insights tend to come suddenly, usually not when sitting at a desk working out the questions, but when relaxing, in the bath, during a walk in the garden etc. During these periods the intuitive mind works and can produce the sudden clarifying insights which give so much joy to scientific research.

Lovelock [6] states that science like art and music is a very intuitive thing. In his research, he asked many scientists how they made a discovery and he got the answer that it came to them in a flash. Scientists also added that, they spent at least two years trying to explain it first to themselves and then perhaps ten to forty years trying to explain it to their colleagues.

As has been known to everybody that the discovery of the "law of gravitation" happened just in the same way. Sir Isaac Newton observed the apple falling from the tree and thought to himself why that apple always descend perpendicularly to the ground. Why doesn't it go sideways or upwards, but perpendicularly to the earth's center? He then answered that there must be a drawing power in the matter: and the sum of the drawing power in the matter of the earth must be in the earth's centre. That's why the apple falls perpendicularly, or towards the centre of the earth. The falling of an apple from a tree, gave birth to the discovery of the law of gravitation. Newton published his discovery in his book Principia in 1687, some 20 years after the incident.

The Greek mathematician, Archimedes is another example to the people who made a discovery using their insights. Archimedes spent days thinking of the problem how to determine whether the king's crown is made up of pure gold or of a mixture of gold with other metals. While taking a bath, he suddenly realized that the volume of the water that run over the top of the tub was exactly equal to the volume of the part of his body that he placed in the water. He ran out the bath to the streets shouting "Eureka, eureka!” The usual bath taking practice awakened intuition of Archimedes and he discovered an everlasting law of physics [7].

Many other scientists emphasize the role of intuitive creative inspiration in their discoveries. For example, the Russian chemist Dimitri Mendeleev worked out for months to find a way to categorize the elements. One night, before falling asleep, he suddenly realized that he should compose "The Periodic Table of Elements" and can categorize the elements by this way. Nicola Tesla said this of his insight that became the basis for the alternating current electrical system: "The idea came like a flash of lightning, and in an instant the truth was revealed". Albert Einstein emphasizes the importance of intuition with these words: "The only valuable thing is intuition.” Albert Einstein also described his theories as the "free invention of the imagination” [5].

\footnotetext{
The tacit knowledge is a significant predictor of success in instruction [4]. Intuition manifests itself as knowledge structures that predispose individuals to think and act in particular ways without much conscious reflection. Therefore students' system of beliefs and intuitions may either match the scientifically accepted concepts or may be incompatible with scientific theories and knowledge. Cahyadi\&Butler [8] assert that students were better able to answer correctly the problems in idealized cases than the problems in real-world cases. They conclude that using contrasting situations (i.e. with and without an idealization) is a useful teaching tool.
}

The notion of intuition has a long history that begins in the discipline of philosophy. The classic view holds that intuition is a form of intellectual process that is separate from conscious thought and that yields qualitatively different knowledge than the explicit reasoning of the conscious mind. The interactionists who oppose classicists agree that intuition is conceptually distinct from reason but locate intuition in the person's interaction with the social world [4].

The root of the word intuition comes from the Latin verb tuere, meaning "to guard, to protect". defines intuition as a handy notion for describing a 
way to make sense of the world - a form of perceiving and thinking that comes to people spontaneously and naturally without much deliberate conscious reflection. Although definitions of intuition and intuitive conceptions vary according to different theorists and researchers, one of the accepted approaches suggests that the human mind benefits from multiple ways to represent knowledge. Some of them operate outside of conscious reasoning and can therefore be considered intuitive. Intuitive conceptions are defined as knowledge or knowledge structures that need not be available to conscious reflection but that act to facilitate or constrain task performance. Intuitive conceptions are a subset of cognitive representations. Hence, intuition can be defined as the process through which intuitive conceptions are acquired and used [6].

According to experimental psychologists, intuition is the phenomenon which occurs "when an individual reaches a conclusion on the basis of less explicit information than is ordinarily required to reach that conclusion”. Sudden appearance, emotional involvement, pre-conscious process, contrast with logical thought, understanding by feeling, creative associations, instinctive knowledge and a subjective certainty of correctness are the properties to intuition.

Reber's and Bowers' definition of intuition are as follows: Reber defines intuition as the end product of an implicit learning experience in which subjects unconsciously learn the associations that exist in the complex patterned information presented [3]. Bowers et al. define intuition similarly as "a preliminary perception of coherence (pattern, meaning, structure) that is at first not consciously represented, but which nevertheless guides thought and inquiry toward a hunch or hypotheses about the nature of the coherence in question” [5]. Similarly, Intuition has been classified differently by different theorists:

\subsection{Poincare’s Classification}

Poincare classified intuition in three categories [9]:

- Intuitions related to the senses and imagination.

- Intuitions expressed in empirical induction.

- The intuition of the pure number, which represents the source of mathematical induction (reasoning).

\subsection{Bahm's Classification}

Bahm has mentioned three types of intuition [3]:

- Objective intuition: immediate capture of the world.

- Subjective intuition: immediate capture of the self.
- Organic intuition: immediate apprehension of the objects and subject together.

\subsection{Piaget's Classifications}

A much more complex classification is made by Piaget in 1966. Firstly, he divided intuitions into two categories; empirical and operational.

- Empirical intuitions refer to the evaluation of physical properties of objects. (for instance, the weight of an object), or to real psychological experiences known by introspection (for instance, the intuition of duration).

- Operational intuitions refer to actions related to objects and psychological phenomena.

Piaget made another classification referring to operational intuitions and mentioned the general distinction between pictorial intuitions, intuitions expressed by images and logico-mathematical intuitions [10; p. 223-225].

According to another classification method referring to the origins of intuitions, one may distinguish primary and secondary intuitive conceptions.

Primary intuitive conceptions are defined as innately specified knowledge structures that are universal to the human species. They develop in individuals independently of any systematic instruction as an effect to their personal experience [4].

In contrast, secondary intuitive conceptions comprise knowledge or knowledge structures that result from learner- environment circumstances that produced them.

\section{Aim of the Study}

In this study we investigated if students from 5th, 6th, 7th and 8th grade levels could develop intuitive conceptions about accelerated and constant velocity motions without conscious attempts to learn the subject, without being presented the explicit knowledge about the subject, but by observing the motion of the objects from a computer animation. The accelerated velocity is represented by a free fall of an apple from a tree. The constant velocity is presented by the flight of a bird towards the apple tree.

The major questions of this study are:

i. Students discriminate between constant velocity and accelerated velocity motion by estimating the position of the objects per unit time?

ii. Does computer animation have a significant effect on discriminating between motion with constant motion, and motion with accelerated velocity?

iii. Are there significant differences among students with respect to grades in so far as to tasks mentioned in the first and second questions? 


\section{Selected conceptions of students}

In the early discussions, the term intuitive is often regarded as standing in opposition to schooled or scientific knowledge. From this perspective, intuitive knowledge is understood in terms of being homegrown and not grounded in the principles of logical organization that underlie educated guess [4].

Recent studies, such as those concerning conceptual change, disclose some of the weaknesses of this earlier view. Investigators working from this perspective are against the tendency to view teachers as providing information through didactic instruction and students are viewed as absorbing correct (i.e., schooled) concepts. Instead, the focus has switched to the nature of conceptual change that starts with what are variously called intuitive concepts, misconceptions and preconceptions. Intuitive conceptions students bring to a learning situation are quite resistant to change through direct instruction [11].

Studies by Lewis and Linn [11], suggest that ignoring the intuitive concepts of students results in school knowledge about scientific phenomena that they are unable to apply in real-world settings. They state that educators should attempt to connect students' naive ideas in the domain to scientific concepts. They also add that the task of the educator is to create cognitive disequilibrium that enforces accommodation of existing concepts through differentiation, extension, or reconceptualization.

Research findings suggest designing the learning environments and guiding instruction taking into account the students' intuitive knowledge in various domains. Dykstra et al. [2] outlined ways that physics teachers could diagnose students' differing conceptions about the relationship between force and motion and then induce them to transform these conceptions.

A common intuitive rule among students is that "constant motion requires a constant force". Watts [12] asked 100 London students, who are 13, 14 and 17 years of age to discuss their idea of force, such as a person sledging down a hill. Many students intuitively believe that constant motion requires a constant force.

Jimoyiannis and Komis asked 90 students (15-16 years old) to compare the final velocities of two balls falling from the same height, one of which has the mass twice of the other. About $50 \%$ of the students told that the speed of the ball is proportional or correlated to its weight. Only $20 \%$ of students anticipated that the balls have the same velocity [13]. Osborne asked the students to identify the total force acting on a thrown tennis ball, on the way up, at the top and on the way down [14]. Only $5.7 \%$ of the students mentioned that the gravitational force is always down to earth in all of the phases of the experiment.
According to Newton's third law action is equal to reaction equal in magnitude and opposite in direction. Savinainen et. al. commonly indicate that most students have problems in understanding Newton's third law [15]. Minstrell asked a physics class at an American high school to draw forces acting on a book stationary on a table [16]. Approximately $50 \%$ of the class believed that gravity and the table were exerting opposite forces. The other $50 \%$ believed that only gravity was exerting a vertical force. Students believe that there is no force acting on the object if it is not moving.

Brown's study showed that only 5\% of the students who have taken traditional high school physics instruction state that the forces will be equal in a head on collision between a large ball and a small one [17]. Most of them generally think that heavier object exerts greater force than the lighter object. Research findings also suggest that conventional instruction is not effective in dealing with misapplications. So, to be aware of students' existing intuitive notions about scientific concepts and to design instructional equipment considering their beliefs is important for educational settings.

Visualization of phenomena through such techniques as computer-animations, simulations, video, demonstrations, and models can contribute to students' understanding of physical concepts by attaching mental images to these concepts. Visualization techniques provide students with visual associations that they may capture. Since they preserve the essence of physical phenomena more effectively than verbal descriptions can visuals enable us to see how things behave.

\section{Procedure of the Study}

We conducted the study in two urban primary schools where majority of students are coming from lower middle class. Totally 283 students were involved in the study. The "force and motion" concepts are studied in Grade 7. Because we did the study at the beginning of first semester in School OPS 5th, 6th and 7th grade students had not studied the science of motion. But we accomplished the study at School KSG at the beginning of the second semester, 7th grade students had just studied the science of motion the others had not covered motion concept by then (See Table 1). Due to time and length limitations in this paper we will present the results for only the total sample. Students' perception of constant or increasing displacement of an object in equal time intervals is the major dependent variable of this study. 
Table 1 . The students participated in the study with respect to their gender and grade levels

\begin{tabular}{|c|c|c|c|c|}
\hline School & Grade & Female & Male & Total \\
\hline \multirow{3}{*}{$\begin{array}{c}\text { Orbay } \\
\text { PS }\end{array}$} & 5 & 24 & 42 & 66 \\
\hline & 6 & 43 & 42 & 85 \\
\hline & 7 & 12 & 12 & 24 \\
\hline \multirow{4}{*}{ KSG PS } & 8 & 5 & 17 & 22 \\
\hline & 6 & 37 & 6 & 43 \\
\hline & 7 & 13 & 13 & 26 \\
\hline & 8 & 5 & 12 & 17 \\
\hline & TOTAL & 139 & 144 & 283 \\
\hline
\end{tabular}

A computer animation was prepared to represent the motion of two different objects namely the free fall of an apple, and the steady flight of a bird. Figure 1 illustrates the user interface of it. One can set a constant velocity for bird and/or control the speed of the motion (i.e. gravitational acceleration, velocity of bird).

Step I: One of the researchers showed the real time computer animation to the students by using a projector in their regular class hour, and in their everyday classroom settings. Bird's speed was set to constant, and gravitational acceleration was set to $\mathrm{g}=10 \mathrm{~m} / \mathrm{sec}^{2}$. Thus we assume that students observed the objects in their original velocities. In the student version of the simulation there was no clue about the "bird's speed". "Speedometer" was slowing down the "bird's speed" and the "gravitational acceleration" simultaneously.

Step II. Right after watching the movie in real time (when $\mathrm{g}=10 \mathrm{~m} / \mathrm{sec}^{2}$ ) the same researcher asked the students to mark the positions of these two objects within six equal time intervals along a straight vertical line and along a straight horizontal line respectively.

We call this task "mark the position" test. The measures obtained from these markings comprise the pretest data. In order to assure the validity of the instrument six teachers who are actively teaching to sixth, seventh and eighth graders gave feedback about the validity of the test software and the "Mark the Position" scale. All of the teachers reported that the tasks expected of students are appropriate for assessing the objectives of the study. Maturation effect is almost none because posttest had been given one hour after the pretest. In this period there is almost no intervention but the animation.

In nature, if the movement of an object occurs too fast human eye may not be able to perceive the details of this motion. In order to comprehend the basic differences between the two motions, the students first watch the animation as authentically as possible, then with slower motion and lastly with the slowest motion.

Step III. After watching the animation in three modes of speed (authentic, slower, slowest), the students were again required to "mark the positions of the apple and of the bird along vertical and horizontal lines respectively for six successive equal intervals of time. This is to be the posttest.

These markings by students were categorized into four main categories:

i. "Increasing", if the object's successive displacements in time intervals is increasing,

ii. "Constant" if all of the displacements are not changing for successive time intervals,

iii. "Decreasing" if it decreases,

iv. "Other" if successive displacements are irregular, random or some regular pattern other than specified above.

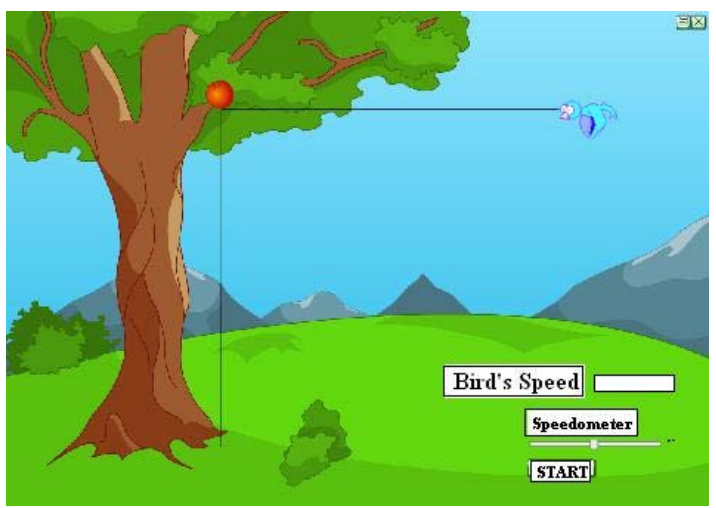

Figure 1. User interface of simulation used in the study (With the courtesy of Volkan Bal)

Two judges scored the markings of students considering the motion of the objects presented in the computer simulation by using the same criteria set by the researchers.. The students who considered the gravitational acceleration of free falling apple as increasing got 1 point from the evaluation for this task. The students who recognized the constant displacement of the bird at successive equal time intervals and reflected this notion by their markings got 1 point for this particular task. The markings endorsed the other categories got 0 point. The correlation between the two sets scores obtained from judges is found to be .793 The correlation between pretest and posttest scores is .822. Judges agreed upon the final categorization of all markings after the reliability check.

\section{Major Findings of the Study}

The Table 2 shows distribution of pretest and posttest markings of all students $(\mathrm{N}=283)$ for apple's motion as they perceive. Although 102 students which is more than one third of all seem to have perceived the gravitational acceleration in the posttest two third of the students did not grasp the concept of acceleration. Table 3 displays the frequencies of all students in terms of their markings of successive displacements of a bird flying with constant velocity. 
Table 2. The students in terms of their markings of successive displacements of a free falling apple

\begin{tabular}{|l|r|r|r|r|r|}
\hline Pretest Apple & \multicolumn{7}{|c|}{ Posttest Apple Displacement } & \multirow{2}{*}{ Total } \\
\cline { 2 - 6 } Displacement & Incrs. & Constant & Decrs. & Other & \\
\hline Increasing & 13 & & & 6 & 19 \\
\hline Constant & 35 & 42 & 10 & 18 & 105 \\
\hline Decreasing & 28 & 4 & 14 & 13 & 59 \\
\hline Other & 26 & 11 & 13 & 50 & 100 \\
\hline Total & 102 & 57 & 37 & 87 & 283 \\
\hline
\end{tabular}

Table 3. The students in terms of their markings of successive displacements of a bird flying with constant velocity

\begin{tabular}{|l|r|r|r|r|r|}
\hline Pretest Bird & \multicolumn{4}{|c|}{ Posttest Bird Displacement } & \multirow{2}{*}{ Total } \\
\cline { 2 - 5 } Displacement & Incrs. & Constant & Decrs. & Other & \\
\hline Increasing & 1 & 4 & 1 & 6 & 12 \\
\hline Constant & 2 & 85 & 6 & 21 & 114 \\
\hline Decreasing & 3 & 31 & 16 & 15 & 65 \\
\hline Other & 5 & 42 & 21 & 24 & 92 \\
\hline Total & 11 & 162 & 44 & 66 & 283 \\
\hline
\end{tabular}

In bird flight case we observe higher tendency to concentrate on the expected choice. 162 students which are more than half of the total group marked the expected displacement pattern for the bird's motion. They seem to have perceived the constant velocity. But there is still a great deal of confusion on the part of the students so far as the displacements of bird at successive time intervals during its steady flight. In some occasional talks with a few students we have learned that they consider the fatigue effect for the bird. It is of course something to be appreciated because the biological realities are as important as the physical ones. This means that entertainment and fantasy could be a hindrance as well as help in teaching.

Table 4 presents the distribution scores before and after the speed controlled computer animation. 264 students out of 283 failed to estimate the correct displacement pattern (increasing) in the pretest. After having watched the computer animation at three speed levels 86 of them seemed to have grasped the right pattern. 6 students who got the answer right at the beginning lost their insight after the treatment. This is hard to explain because the expected pattern is quite a sophisticated one and there is almost no chance factor involved.

Table 4. Pretest and posttest scores for the displacements of the free falling apple

\begin{tabular}{|c|r|r|r|}
\hline \multirow{2}{*}{$\begin{array}{c}\text { Displacements for } \\
\text { free falling Apple }\end{array}$} & \multicolumn{2}{|c|}{ Posttest Score } & \multirow{2}{*}{ Total } \\
\cline { 2 - 3 } & Incorrect & Correct & \\
\hline Pretest Incorrect & 178 & 86 & 264 \\
\hline Pretest Correct & 6 & 13 & 19 \\
\hline Total & 184 & 99 & 283 \\
\hline
\end{tabular}

Pearson Chi-square value for the Table 3 is 10,013 which indicates a frequency concentration within the cells significantly $(\mathrm{p}<, 000)$ different than that expected of a random distribution. As can easily be seen the ignorance and the conceptual chaos still prevails. As a matter of fact 178 students who could not change their conception even after the speed controlled demonstration to make their perceptions better. They still cannot conceive increasing displacements per equal time intervals.

According to pretest results, among the students who do not have explicit knowledge about 'force and motion' topic and who didn't study this topic in their schools, only 19 students were able to "discover" the effect of gravitation on free falling apple. Only 13 of them maintained their understanding in the posttest as well. The average of science achievement scores of these 13 students is 3.93/5. In the pretest, even the students who have high science grades did not take into account the gravitational effect acting on free falling object while drawing the motion of free falling apple. In the pretest, it is observed that many students had high tendency to mark the position of two objects as having equal displacements in equal time intervals without taking into account the gravitational force acting on free falling object.

Table 5 exhibits the distribution of the scores before and after the speed controlled computer simulation for the bird flying steadily.

Table 5. Pretest and posttest scores for the displacements of the bird flying with constant velocity

\begin{tabular}{|c|r|r|r|}
\hline $\begin{array}{c}\text { Displacements of bird } \\
\text { flying with constant } \\
\text { velocity }\end{array}$ & \multicolumn{2}{|c|}{ Posttest Score } & \multirow{2}{*}{ Total } \\
\cline { 2 - 3 } & Incorrect & Correct & \\
\hline Pretest Incorrect & 92 & 77 & 169 \\
\hline Pretest Correct & 29 & 85 & 114 \\
\hline Total & 121 & 162 & 283 \\
\hline
\end{tabular}

169 students out of 283 failed to estimate the correct displacement pattern (constant) in the pretest. After having been exposed to the computer simulation at three speed levels 77 of them seemed to have taken hold of the right pattern. 29 students who got the point right at the start lost their insight after the reinforcing conduct. This is also very hard to explain because the expected pattern is relatively easier to perceive. There must be a powerful factor to distract many of the students. First reason which rushes in mind again is that of a living organism is not an appropriate object to animate a physical reality. Pearson Chi-Square for Table 5 is 23,391 which denotes a strong bias $(\mathrm{p}<, 001)$ in frequency distribution within the cells of the cross-tabulated data.

The figures within the other cells are very close to each other. More than half of the students marked the expected (constant) displacements for the bird in 
the posttest. But the unawareness and the conceptual disorder still exist. As a matter of fact, 121 students who could not have altered their conception even after the demonstration to make their perceptions better. They still cannot perceive equal displacements of bird within equal time intervals. We tested the significance of the changes between pretest and posttest scores by using the Wilcoxon signed ranks test, and also with McNemar test. Results are given in Table 6.

The figures in Table 6 shows that 86 students corrected their conceptions about the displacement of free falling apple. Also 77 students changed in positive direction so far as their perceptions about the displacements of the motion with constant velocity are concerned. There are only 6 students who somehow went in the wrong direction despite the guidance about the motion of a free falling apple. The number of deteriorated conceptions equals 29 so far as the steady flight of the bird is concerned.

Table 6. The comparison of pretest and posttest scores for two different types of motion

\begin{tabular}{|r|c|c|}
\hline Relative Rank of Scores & Free fall & $\begin{array}{r}\text { Constant } \\
\text { Velocity }\end{array}$ \\
\hline $\begin{array}{r}\text { Posttest score greater than } \\
\text { Pretest score }\end{array}$ & 86 & 77 \\
\hline $\begin{array}{r}\text { Posttest score equals } \\
\text { Pretest score }\end{array}$ & 191 & 177 \\
\hline $\begin{array}{r}\text { Posttest score smaller than } \\
\text { Pretest score }\end{array}$ & 6 & 29 \\
\hline Total & 283 & 283 \\
\hline $\begin{array}{r}\text { Wilcoxon } \\
\text { signed ranks: Z }\end{array}$ & $-8,341$ & $-4,662$ \\
\hline $\begin{array}{r}\text { McNemar } \\
\text { Chi-Square }\end{array}$ & 67,837 & 20,840 \\
\hline Asymp. Sig. &, 000 &, 000 \\
\hline
\end{tabular}

For the ones who can be satisfied with the statistical significance of change "before and after" the treatment the effect of computer animation is superb. However 191 wrong conceptions about the accelerated motion could not have been changed by the treatment. The wrong conceptions of 177 students remained the same about the motion with constant velocity.

The correlations between pretest, posttest and overall science achievement scores of students are given in Table 7 . The correlation between pretest score and science achievement score is not significant. The other two correlations are significantly high $(\mathrm{p}<, 001)$ although not absolutely. The correlational analysis implies that whatever (aptitude, motivation, interest etc.) makes up the overall scholastic achievement is still a factor to be considered in instructional designs.
Table 7. The correlations between science achievement, pretest and posttest scores of students

\begin{tabular}{|l|l|c|c|}
\hline \multicolumn{2}{|l|}{} & $\begin{array}{c}\text { Score on } \\
\text { Pretest }\end{array}$ & $\begin{array}{c}\text { Score on } \\
\text { Posttest }\end{array}$ \\
\hline $\begin{array}{l}\text { Science } \\
\text { Achievement }\end{array}$ & $\begin{array}{l}\text { Pearson } \\
\text { Correlation }\end{array}$ &, 018 &, $287^{*}$ \\
\hline & $\mathrm{N}$ & 281 & 281 \\
\hline & & & \\
\hline $\begin{array}{l}\text { Score } \\
\text { Pretests }\end{array}$ & $\begin{array}{l}\text { Pearson } \\
\text { Correlation }\end{array}$ & &, $231^{*}$ \\
\hline \multicolumn{3}{|l|}{$\mathrm{N}$} & 283 \\
\hline * Significant at p<0,001 level.. \\
\hline
\end{tabular}

The correlational analysis implies that whatever (aptitude, motivation, interest etc.) makes up the overall scholastic achievement is still a threshold factor to be considered in instructional designs. Insignificant correlation between Science achievement an pretest scores on research.

Insignificant correlation between Science achievement and pretest scores on research tasks , but significant positive correlations between the same variables in the posttest confirms the old belief: Success breeds success.

Students are classified in four categories in terms of their responses about the flight of the bird and free fall of an apple: Correct responses for both; incorrect for both; correct for the apple but not for the bird, and finally correct for the bird but incorrect for the apple. Naturally frequencies of students within each category differs in the pretest and in the posttest. ANOVA results in Table 8 show that the group of 7 students who gave correct responses for both tasks has significantly highest average in science achievement. Science achievement levels of the other groups in the pretest are not significantly different.

Table 8. Homogeneous subsets of the mean scores in Science courses w.r. to response categories in the pretest

\begin{tabular}{|l|c|c|c|}
\hline Pretest Response N & $\mathbf{N}$ & $\mathbf{1}$ & $\mathbf{2}$ \\
\hline $\begin{array}{l}\text { Apple Incorrect \& Bird } \\
\text { Correct }\end{array}$ & 107 & 2,84 & \\
\hline Apple \& Bird Incorrect \& Bird & 12 & 3,92 & 3,92 \\
\hline $\begin{array}{l}\text { Apple Correct \& } \\
\text { Incorrect }\end{array}$ & 7 & & 4,43 \\
\hline Apple \& Bird Correct & & & \\
\hline $\mathrm{P}<0,05$ & & & \\
\hline
\end{tabular}

Students were classified again after the posttest w.r. to their responses about the displacements of the apple and that of the bird. ANOVA to test the significance of the differences between the science achievement means of different response categories yielded. The Table 9 indicates that there are basically two distinct groups: The ones who can identify the apple's gravitational acceleration, and the ones who cannot. 
Table 9. Homogeneous subsets of the mean scores in Science courses w.r. to response categories in the posttest

\begin{tabular}{|l|c|c|c|}
\hline Posttest Response & N & 1 & 2 \\
\hline Apple Incorrect and Bird Correct & 101 & 2,49 & \\
\hline Apple \& Bird Incorrect & 83 & 2,80 & \\
\hline Apple Correct \& Bird Incorrect & 38 & & 3,66 \\
\hline Apple \& Bird Correct & 61 & & 4,07 \\
\hline $\mathrm{P}<0,05$ & 283 & & \\
\hline
\end{tabular}

The remarkable increase in the frequency of those who can grasp the acceleration of apple's free-fall in the posttest point out the effectiveness of the demonstrative computer animation.

\section{Conclusions}

The construct we would like to measure is "intuition" but we might have measured previous knowledge, success by intelligent guessing, chance success by random guessing etc.

Most important question in so far as validity concerned is that "are we measuring intuition or perception?” If people were as tall as Pisa tower, and the gravitational acceleration were one tenth of what it is on earth now wouldn't they have discovered gravitational acceleration earlier? Most probably they would have been able to observe it directly rather than to infer it from experiments.

There are so many studies investigating why understanding complex information is difficult. According to Redish, mastery of abstract scientific concepts requires building flexible and runnable mental models [18]. Gravity is one of the abstract concepts. Trying to teach students the gravitational acceleration concepts by presenting explicit information with rote manipulation of symbols and formulas may result in students' formations of those flexible mental models with no-real life experiences. The flexible mental models may in time turn into misconceptions that are resistant to change even after participating in courses. McDermott asserts that Learning science need to be able to sift through complex information, identifying what is important and what is not and recognizing critical patterns and relationships [19].

The main focus of this study was to investigate if students could intuitively discover how the natural world functions without conscious attempts to learn the content, and without being exposed to explicit information, theories or formulas,. Although we have observed a significant improvement to realize the objectives of the study the students could not have achieved mastery in learning. The more the instruction gets individualized the higher the achievement will be.

In this study before the formal representations of abstract concepts the students can intuitively construct their own knowledge about how the natural world functions. Fostering the ability of students to predict qualitatively the behavior of phenomena under investigation is a constructive method for teaching them how to manipulate quantitative formulas. Students may use their experiences gained from computer simulations to construct more accurate mental models and to form a bridge between real-world phenomena and scientific formalisms.

However we should note that educational media is not an alternative to the whole instructional system - There are many other components and characteristics of instructional system which are to be carefully designed and controlled [20].

The method used in this study can also be used to get information about students' preexisting intuitive conceptions about other abstract concepts and to help them to construct a bridge between real-world phenomena and abstract formalisms. Only onedimensional motion is concerned within this study. In further studies, students' intuitive conceptions about two-dimensional motions, such as trajectory motion, circular motion may be investigated. After investigating students' predictions, the students can compare their mental models with the operation of real-world phenomena.

It cannot be concluded that the treatment procedure had caused mastery learning. Slightly more than one third of the participants could have achieved the objectives of the study. Because the achievement in this study depends on students' observation and making comparison skills, and their ability to construct their own knowledge, the subjects who are used to lecture based traditional instruction, may not be ready for constructivist or discovery learning.

The limited time for instruction, and crowded classes were major setbacks in this study. Some of the students may have need extra time specified for the treatment procedure. Before being presented the abstract theories and formulas, if student get chance to be in situations that they can first make predictions, then they can observe how natural phenomena operates and make comparisons, abstract concepts may eventually become less complex and more lucid for the students. With the help of this method, students may construct more accurate mental models and may be more successful in constructing a bridge between real-world phenomena and scientific formulas.

The method used in this study can be an efficient starting point for instruction. Before the formal representations of abstract concepts are introduced, with the help of model used in this study the students can intuitively understand how the natural world functions. Fostering in students the ability to predict qualitatively the behavior of phenomena under investigation is a valuable method for teaching them 
to manipulate quantitative formulas. Students may use their experiences gained from computeranimation supported instruction to construct more accurate mental models and to form a bridge between real-world phenomena and scientific formalisms.

\section{References}

[1] Elkind, D. "Children's Discovery of Mass, Weight and Volume”, in I. E. Sigel and F. H. Hooper, (Eds.), Logical Thinking in Children. New York: Holt, Rinehart and Winston. 1968, pp. 425-426.

[2] Dykstra, D. I., C. F. Boyle; I.A. Monarch. "Studying conceptual change in learning physics". Science Education, 76(6), 1992, pp. 615-652.

[3] Reber, A. "Implicit learning and Tacit Knowledge". New York: Oxford University Press, 1993.

[4] Torff, B., R.J. Sternberg. "Understanding and teaching the intuitive mind: Student and teacher learning".

New Jersey: Lawrence Erlbaum Associates, Publishers, 2001.

[5] Bowers, K., G. Regehr, C. Balthazard, K. Parker, "Intuition in the context of discovery". Cognitive Psychology, 22, 1990, pp. 72-110.

[6] Lovelock, J. “Goi Peace Foundation Report”, p.18. www.intuition-in-service.org/intuitionQuotations.cfm?auth or=45. (10 January 2010).

[7] Roberts, R. M. Serendipity, Accidental Discoveries in Science. New York: Wiley Science Editions, 1989, pp. 115.

[8] Cahyadi, M. V., \& P.H. Butler. "Undergraduate students' understanding of falling bodies in idealized and real-world situations”, Journal of Research in Science Teaching, 41, 6, 2004, pp. 569-583.

[9] Poincare, H. L. The Value of Science, New York: Dover Publications Inc, 1920.

[10] Beth, E.W., J. Piaget. Mathematical Epistemology and Psychology. Dordrecht: Reidel, 1966.

[11] Lewis, E.L., M.C. Linn. "Heat Energy and Temperature Concepts of Adolescents, Adults and Experts: Implications for Curricular Improvements", Journal of Research in Science Teaching, 31, 6, 1994, pp. 657-677.

[12] Watts, D.M. “A study of school children's alternative frameworks of the concept of force". European Journal of Science Education, 5, 2, 1983, pp. 217-230.

[13] Jimoyiannis, A. \& V. Komis. "Computer simulations in physics teaching and learning: a case study on students' understanding of trajectory motion”. Computers \& Education. 36, 2, 2001, pp. 183-204.
[14] Osborne, R. "Science education: where do we start?”, Australian Science Teachers Journal, 28, 1, 1982, pp. 21-30.

[15] Savinainen, A., P. Scott, J. Viiri. "Using a bridging representation and social interactions to foster conceptual change: Designing and evaluating an instructional sequence for Newton's third law", Science Education. 89, 2005, pp. 175-195.

[16] Minstrell, J. “Explaining 'at rest' condition of an object”. The Physics Teacher, 20, 1982, pp. 10-14.

[17] Brown, D.E. "Students' concept of force: The Importance of understanding Newton's third law”, Physics Education, 24, 1989, pp. 353-358.

[18] Redish, E., "The Implications of Cognitive Studies for Teaching Physics", American Journal of Physics, 62, 9, 1993, pp. 796-803.

[19] McDermott, L.C. "Millikan Lecture 1990: What We Teach and What is Learned-Closing the Gap", American Journal of Physics, 59, 1991, pp. 301-315.

[20] Baykal, A. "Open systems metaphor in instructional design”. Procedia: Social and Behavioral Sciences.1, 2009, pp. 2027-2031. www.indeksiletisim.com/images/ma kale/sdarticle.pdf (28 January, 2010). 